\title{
LA PRESENCIA DEL ESPÍRITU EN LOS ESCRITOS DE SAN PABLO
}

\section{Resumen}

El rol y sentido del uso del término "espíritu” en Pablo es materia de debate. Hay autores que la niegan prácticamente, mientras otros la entienden como principal en el pensamiento del Apóstol. Sin duda, el tema está muy ligado a lo cristológico, pero con fuerte connotación comunitaria (eclesial) y escatológica.

En 1 Corintios el tema aparece ligado a los más débiles y despreciados de la comunidad ante aquellos que se creían poseedores de la espectacularidad espiritual. En Gálatas contrasta con la debilidad. Señala la fuerza de la comunidad en medio del mundo y sus elementos que le son hostiles ("la carne"). En Romanos, la novedad de Cristo es inalcanzable sin la gracia, el don del espíritu, que alcanza a los que "están en Cristo" la plena libertad; es el que nos hace "andar" según Dios. Las grandes dificultades de la violencia extrema no impiden la unión de amor con Cristo.

El espíritu es la expresión de una nueva creación que ha comenzado, en la que se manifiesta un mundo según el proyecto de Dios.

Palabras clave: Espíritu. Cuerpo/carne. Escatología. Debilidad. "Vivir según el espíritu".

... the Spirit is the apocalyptic-eschatological presence of God and Christ on earth, in human history ${ }^{1}$.

1 M. C. DE Boer, "Paul and apocalyptic-eschatology”, en J. J. Collins (ed.), Encyclopedia of apocalypticism, vol. I, New York 1998, 357. 
Hacer mención del "espíritu" en los escritos seguramente paulinos resulta difícil ${ }^{2}$. Por un lado hay "teologías de Pablo" que poca o casi nula cabida dan al tema ${ }^{3}$, y por otro hay autores que afirman que este constituye el "centro" mismo de la teología paulina ${ }^{4}$, que es una creación del Apóstol ${ }^{5}$ o que el tema no se diferencia de Cristo, constituyendo casi un sinónimo del mismo ${ }^{6}$. Para ser precisos sería sensato mirar no solo la totalidad de las veces que el término pneuma (y sus derivados) se encuentra en las cartas auténticas de Pablo, sino también ver la progresión que el término muestra en las mismas ${ }^{7}$, pero eso es algo que excede nuestras posibilidades en este escrito.

La importancia del tema puede quedar expresada en dos citas de autores contemporáneos: "El Espíritu está cerca del centro de las cosas para Pablo como parte fundamental del corazón de su comprensión del Evangelio";;

2 Para empezar, y lo señalaremos, no es fácil saber si ha de escribirse "espíritu" o "Espíritu". Obviamente no es problema de los escritos bíblicos, para los cuales no existen las minúsculas, pero es doblemente difícil a partir de los concilios y el reconocimiento del Espíritu como "persona" divina. Muchos autores utilizan la "E" mayúscula cuando se trata de Espíritu divino y la "e" minúscula cuando se trata de espíritu humano, lo cual, en muchos casos, es hipotético. Sin intenciones de tomar posición en este tema, en este trabajo utilizaremos la minúscula salvo cuando los autores citados utilizan la mayúscula.

3 Puede verse el limitado espacio que dedica al tema J. Sánchez Bosch, Maestro de los pueblos. Una teología de Pablo, el Apóstol, Estella 2007. Es ejemplo de esto que en S. Westerholm (ed.), The Blackwell Companion to Paul, Oxford 2011, no haya un capítulo dedicado al espíritu. Algo semejante ha ocurrido con la carta a los Hebreos, cf. J. Levison, "A Theology of the Spirit in the Letter to the Hebrews", CBQ 78 (2016) 90-110.

${ }^{4}$ P. Rondez, “Ein Zentrum paulinischen Theologie? Eine Pneumatische Erschliessung des Zusammenhangs von Soteriologie und Christologie anhand von Gal 5:25", en A. DettwiLer - J. Zumstein (eds.), Kreuzestheologie in Neuen Testament, Tübingen 2002, 59-79.

5 "Pablo es el iniciador de la teología escrita sobre el Espíritu”, F. PASTOR RAmos, Para mí, vivir es Cristo. Teología de san Pablo. Persona, experiencia, pensamiento, anuncio, Estella 2010, 244.

6 Varios autores "en el pasado" han propuesto una identificación entre Cristo y espíritu, cf. ib., 249.

7 Así, por ejemplo, H. LonA, “Elementos de pneumatología paulina”, Proyecto 31 (1998) 5-48, F. W. Horn, “Holy Spirit”, Anchor Bible Dictionary, III, new York 1992, 260 280; brevemente, J. D. G. DunN, The Theology of Paul the Apostle, Edinburgh 1998, 419-425; M. Winger, "The Meaning of Pneûma in the Letters of Paul: A Linguistic Analysis of Sense and Reference", CBQ 78 (2016) 706-725.

8 G. D. FEE, Paul, the Spirit and the People of God, Massachusetts 1996, 7. 
"La doctrina paulina del espíritu es por lejos más central y característica que su doctrina de la justificación por la fe" 9 .

Siguiendo a A. C. Thiselton podríamos resumir el tema del espíritu en Pablo en ocho temas básicos ${ }^{10}$ :

1) Cristocentrismo del espíritu; cita a Dunn ("La experiencia de Pablo de Cristo y del Espíritu fueron una, y a Cristo lo experimentó a través del Espíritu") y a Whiteley ("El Espíritu Santo es el sello distintivo del cristiano").

2) La recepción del espíritu por todo cristiano (algo opuesto al judaísmo rabínico).

3) El espíritu como un regalo especial para algunos elegidos, aun cuando hay una efusión del espíritu sobre toda la comunidad.

4) El espíritu como el agente de la resurrección (cf. Rom 8,11), la nueva era, los últimos días.

5) El papel del espíritu en la difusión del Evangelio; la teoría paulina del espíritu es más comunitaria que individual, más escatológica que natural.

6) El espíritu como el portador del poder y la presencia de Dios; es "santo" porque da el poder y presencia del mismo Dios, su acción -por tanto- es más que natural; en Pablo es lo opuesto al espíritu de este mundo (qôdes es algo reservado al Dios vivo).

7) Papel transformador del espíritu en vista de nuestro destino futuro.

8) Papel profético y revelador del espíritu.

No puede entenderse la teología de Pablo sin ver cómo el espíritu la atraviesa de punta a punta, en especial porque es inseparable de la gracia. La centralidad del don del espíritu en y como comienzo del discipulado cristiano es uno de los principios fundacionales de la obra de Pablo como evangelista, pastor y teólogo ${ }^{11}$. De hecho, con razón U. Schnelle lo presenta como "principio de conexión" del pensamiento paulino: la teología, la cristología, la soteriología, la antropología, la ética y la escatología ${ }^{12}$.

9 S. NEIL - N. T. WRIGHT, The Interpretation of the New Testament 1861-1986, Oxford 1988, 203; "en suma, no tendrán la doctrina paulina de la garantía [assurance] ly la gloria de la doctrina reformada de la justificación es precisamente seguridad) sin la doctrina paulina del Espíritu", N. T. WRIGHT, Justification. God's plan \& Paul's visiin, Downers Grove (IL) 2009, 237.

10 A. C. Thiselton, The Holy Spirit in Biblical Teaching, through the Centuries and Today, Grand Rapids (MI) - Cambridge 2013, 70-74.

11 Puede verse T. Paige, "Holy Spirit”, en G. F. Hawthorne y otros (eds.), Dictionary of Paul and his Letters, Downers Grove (IL) - Leicester 1993, 404-413.

12 U. Schnelle, Apostle Paul. His Life and Theology, Grand Rapids (mI) 2005, 486-490. 
Es evidente que el término es en su origen un antropomorfismo (soplo, aliento). El espíritu humano muestra una dimensión de la persona en su capacidad dinámica, aunque también se alude a una dimensión natural (viento).

Aunque no hay uniformidad, como es propio del judaísmo, es muy frecuente sostener que el "espíritu" se ha retirado de Israel (alguno, quizá exageradamente, lo ha llamado "teología oficial") ${ }^{13}$, Dios se ha alejado de su pueblo y recién lo enviará en un futuro indeterminado. La expectativa en un profeta (como Moisés o como Elías) anuncia la llegada de los tiempos escatológicos o quizá mesiánicos.

La resurrección de Jesús manifiesta para sus seguidores la llegada de la "nueva era" anunciada por Dn 12,2; una "nueva era" que es inseparable del mismo Cristo resucitado. Esta era presenta una novedad disociativa para el movimiento de Jesús, puesto que, aunque ya ha comenzado, aguarda todavía la inminente venida de Jesús para vivirse en plenitud ${ }^{14}$. Con la pregunta por la identidad del Nazareno comienza la pregunta cristológica, pero esta es inseparable de la respuesta escatológica. Este Jesús, reconocido como Mesías, Señor e Hijo de Dios por los primeros seguidores, lo experimentan como algo ya ocurrido, puesto que el don escatológico por excelencia, el espíritu de Dios, se ha derramado. Solo poseyendo el espíritu la comunidad primitiva puede reconocer a Jesús como Hijo (Rom 1,4) o como Señor (1 Cor 12,3).

La secta de los nazarenos está marcada por su reclamo de haber recibido el espíritu de Dios de un modo nuevo y excepcional. Como se dijo, muchos afirman que la profecía ha cesado (en el período del Segundo Templo) y el espíritu se ha retirado (cf. 1 Mac 4,46); pero ahora Pablo se ve a sí mismo como profeta. La teología de Mateo y Marcos (en menor medida Lucas) ve a Juan el Bautista como Elías, el espíritu es "derramado" (Isaías, Ezequiel, Joel), se "bebe" (1 Cor 12,13). La confianza en la donación del espíritu fue tan decisiva como la resurrección de Jesús.

Pero el espíritu no solamente se ha infundido sobre toda la comunidad creyente como don, sino que también se derrama -como es habitual en la Biblia hebrea- sobre algunos miembros para una misión particular. Pablo es consciente de que él ha recibido el espíritu y ha sido llamado por Dios como profeta de los tiempos escatológicos, como un nuevo Elías, lleno de celo por Dios, llamado desde el seno de su madre a

13 E. Schwelzer, El Espíritu Santo, Salamanca 1984, 46-47. 75.

14 "El Espíritu es la clave de la doctrina cristiana del fin", Thiselton, Holy Spirit, 
realizar "signos y prodigios", anunciando la venida inminente del Señor y de su "día" 15 .

"Espíritu" es un término nacido de la experiencia ${ }^{16}$, experiencia de vida y libertad/liberación. Y está estrechamente ligado al bautismo ${ }^{17}$. Experimentar la presencia del espíritu no es contradictorio para Pablo, que a su vez experimenta la debilidad. El espíritu de Dios es cristocéntrico, comunitario y escatológico ${ }^{18}$. El lenguaje paulino tiene ambigüedades, particularmente porque no es fácil en muchos casos -como se dijo- saber si correspondería usar mayúscula o minúscula ${ }^{19}$.

Hay discusiones posteriores sobre el Espíritu y Cristo, como señala Thiselton $^{20}:$ 1) el Espíritu no apunta a sí mismo, sino a Cristo; 2) frecuentemente hay confusión de los "medios del Espíritu" con "el Espíritu" (algo que Fison llama "confusión idolátrica") 21, 3) confundir al Espíritu con sus manifestaciones es reducirlo y rebajarlo de su ser casi personal. Es el caso de Corinto, donde algunos confunden al espíritu de Cristo "con el pneuma arrebatante de las experiencias místicas griegas y sustituto de la inteligencia (nous) humana" ${ }^{22}$.

15 Cf. E. de La Serna, “Pablo, ¿el precursor? Pablo y las tradiciones sobre Elías”, RevistB 75 (2013) 161-180.

16 “... los inicios son un momento privilegiado por la cercanía de Jesús, por el entusiasmo existente (inseparable de la peculiar experiencia del Espíritu en la fe cristianal porque se realizaron opciones decisivas que marcaron la historia posterior", R. Aguirre, La memoria de Jesús y los cristianismos de los orígenes, Estella 2015, 131.

17 “El uso de Pablo de la idea helenística pneuma revela las dificultades que tiene con él. Para él, el espíritu está dado en el bautismo como una posesión cristiana común. Esta mirada puede ser correlativa con su comprensión de la ekklêsía como una entidad que, si es el pueblo de Dios escatológico, sin embargo está en el mundo y está sujeto a las vicisitudes de la existencia histórica. La identidad del cristiano no puede ser pensada sin referencia práctica a su entorno social”, J. H. ScHütz, Paul and the Anatomy of Apostolic Authority, Louisville - London 2007, 255.

18 "Es indudable que entre Kyrios y Pneuma existe una relación estrechísima, como también es muy estrecha la que existe entre Dios y el Espíritu. Tanto la acción de Cristo resucitado como la acción de Dios se experimentan en el Espíritu. Se puede afirmar incluso que la identidad de acción entre el Kyrios y el Pneuma es un elemento propiamente paulino", J. GNILKA, Teología del Nuevo Testamento, Madrid 1998, 113.

19 Thiselton, Holy Spirit, 76. Algo semejante sostiene J.-N. Alettı, "Paul's Exhortations in Gal 5,16-25. From the Apostle's Techniques to His Theology", Biblica 94 (2013) 401, nota 14.

20 ThISELton, Holy Spirit, 78.

21 J. E. FISon, The Blessing of the Holy Spiri, London - New York 1950, 22, citado por THISELTON, Holy Spirit, 78.

22 G. Barbaglio, La teología de san Pablo, Salamanca 2005, 455. 
Hay un sistema cristológico para el cual todos reciben el espíritu y un sistema veterotestamentario en el cual el espíritu se da a algunos para el ministerio $^{23}$. En este último, el espíritu es solo cumplimiento de las esperanzas de los últimos días; en el sistema cristológico se trata de completar la obra y ministerio de Cristo. El espíritu da al cristiano la misma intimidad con Dios que Cristo tuvo.

La referencia a Jesús glorificado y al don del espíritu son entonces prácticamente inseparables, aunque aludan a aspectos muy diferentes ${ }^{24}$.

Mirando algunas perícopas clave en las cuales el término pneuma ocupa un lugar central, y sabiendo que es mucho lo que quedará por decir, señalemos aspectos principales de la presencia o envío del espíritu de Dios sobre la comunidad.

\section{El espíritu y la opción por los pobres (1 Corintios)}

La unidad de 2,6-16 25 está caracterizada por el uso de la primera persona del plural ${ }^{26}$; tiene la apariencia de un midrás, comenzado y con-

23 A. C. Thiselton, The Living Paul. An Introduction to the Apostle's Life and Thought, Downers Grove (IL) 2009, 59.

24 En E. de la SeRna, “Aproximación a la teología paulina”, Theologica Xaveriana 165 (58/1) (2008) 51-85, hemos propuesto que la cristología, la escatología, la antropología y la eclesiología en Pablo casi no se entienden separadamente, ya que Pablo pasa de una a otra con suma facilidad. H. P. van Dusen afirma que "la relación entre Cristo y el Espíritu Santo constituye la contribución más original de Pablo a la concepción cristiana del Espíritu Santo", H. P. van Dusen, Spirit, Son and Father, New York 1958, 66, citado por A. ThISELTon, Holy Spirit, 79.

25 “De todos los pasajes de 1 Corintios, la exégesis de 2,6-16 es quizá la más complicada", J. Murphy O'Connor, “Interpolations in 1 Corinthians”, CBQ 48 (1986) 81-94 (81).

26 M. Widmann propone que esta perícopa es una interpolación no paulina, "1 Kor 2:6-16: Ein Einspruch gegen Paulus", ZNW 70 (1979) 44-53; cosa que reafirma W. WALKER, "1 Corinthians 2:6-16: A Non-Pauline Interpolation?", JSNT 47 (1992) 75-94, respondiendo a las críticas de J. Murphy O'Connor a aquel ("Interpolations"); también H. Conzelmann, 1 Corinthians (Hermeneia), Philadelphia 1975, 57 ("términos escatológicos [...] tomados del lenguaje de los misterios"). E. E. ELLIs propone que es prepaulino y Pablo la adapta: "Traditions in 1 Corinthians", NTS 32 (1986) 490. G. D. FEE, The First Epistle to the Corinthians (NICNT), Grand Rapids (MI) 1991, 100 ("está usando su lenguaje"), y A. C. ThISELton, The First Epistle to the Corinthians (NIGTC), Grand Rapids - Cambridge 2000, 224 (“Pablo toma las palabras clave [...] y reclama los términos para el Evangelio"] proponen que Pablo toma temas o términos corintios y los reubica. Mark Taylor muestra claramente nueve elementos centrales de la unidad que son comunes y coherentes con el resto de la carta: M. TAYLOR, 1 Corin- 
cluido por un texto de la Escritura, y con semejanza a 1,18-31 (en ambas unidades Pablo contrasta la sabiduría humana y la sabiduría divina); ambas secciones (1,18-31 y 2,6-16) finalizan con una unidad en la que Pablo habla de su ministerio (comenzada cada una por kagô, 2,1; 3,1). La palabra de Pablo ("hablamos" es el leitmotiv de la unidad, vv. 6.7.13) es intracomunitaria, dirigida a los teleiois (v. 6), estos son los que tienen "la mente" (nous) del Señor. Se refiere a "hablar" (no a "proclamar", con lo que prepara el hablar profético del cap. 14). Lo hablado es la "sabiduría de Dios" 27. El contraste es entre theos y anthropos ${ }^{28}$ y entre el espíritu divino y el espíritu humano (contraste que se encuentra en la cita mencionada en v. 9 y es particularmente importante en v. 11) ${ }^{29}$. El agente del obrar divino es el espíritu de Dios, espíritu de revelación, y es el mismo espíritu el que permite la aceptación para reconocer los dones de Dios, porque conoce las cosas de Dios (v. 11), viene de Dios (v. 12) es "de Dios" (vv. 11.14). Lo que es comunicado por el espíritu de Dios es la sabiduría de Dios, y esto permite a Pablo destacar qué sabiduría es de Dios y cuál no, sino que es "de los príncipes de este tiempo" (vv. 6.9). Los diferentes términos antropológicos de 2,6-16 (espíritu de la persona, persona natural...) contrastan una persona "natural" (psyjikós) con una persona "espiritual" (pneumatikos), una que ha recibido el don del espíritu de Dios.

La perfección (y el contraste con la infancia; ¿relacionada con la diferencia entre la "leche" y el "alimento sólido"?), ¿alude a los "espirituales"? Parece que los adversarios corintios entienden que la madurez se define en clave de "conocimiento", mientras que Pablo la define en términos de "edificación" (cf. 8,1). No ha de descuidarse que toda esta gran unidad

thians (The New American Commentary 28), Nashville (TN) 2014, 84 nota 222. S. GRINDHEIM propone que se comprende la unidad más claramente en el contexto de las discusiones retóricas de su tiempo, “Wisdom for the Perfect: Paul's Challenge to the Corinthian Church (1 Corinthians 2,6-16)", JBL 121/4 (2002) 691 (explicitado en nota 5).

27 Siendo el tema del presente trabajo el "espíritu", no podemos detenernos en la importancia de la cristología y Sofía. La bibliografía sobre la misma es abundante, particularmente en la teología feminista.

28 Así lo afirma S. Butticaz, “Vers une anthropologie universelle? La crise galate: fragile gestion de l'ethnicité juive", NTS 61 (2015) 505-524 (510-513).

29 Como otras citas veterotestamentarias de esta unidad, esta no pertenece expresamente a autores bíblicos. Se ha hablado de "florilegio" (cf. L. CERfaux, "Vestiges d'un florilege dans 1 Cor 1.18-3.24", RHE 27 [1931] 521-34); de una combinación de citas -Isaías y Jeremías, en este caso-, de versión libre o incluso -en este texto- de un apócrifo, Apocalipsis de Elías, según Orígenes (cf. THISELTON, First Corinthians, 252; él lo llama "pastiche of biblical allusions", 253). 
(1 Cor 1-4) está marcada por la "iniciativa divina" ${ }^{30}$. Esta sabiduría divina es inaccesible sin mediar la revelación (no puede adquirirse por la propia inteligencia o capacidad), solo puede adquirirse por el espíritu, que sondea las profundidades de Dios. Hans Conzelmann ha señalado justamente que quienes utilizan este lenguaje son las clases altas ${ }^{31}$. "Perfectos" puede ser un término de los corintos o de Pablo mal utilizado por estos, que él universaliza como "don de Dios" (como lo hará también en 1 Cor 12) y no por capacidad humana; y lo relaciona con la cruz, que no es de este "eón". Madurez, sabiduría y ser "espirituales" se identifican en la mirada paulina. No es evidente a quiénes se refiere con el "nosotros" de v. 10, ¿a los predicadores?, ¿a todos los cristianos? Lo cierto es que hay quienes tienen conocimiento y quienes no, y la diferencia entre ambos radica en tener o no el espíritu; la terminología del "espíritu" es la dominante en el resto de la unidad. Es interesante que la cita de Is 40,13, donde dice "quién midió la rúaj de Yahvé", la versión de los LXX la traduce por "mente [nous] del Señor", la cual Pablo cita, quizá viéndolos aquí como sinónimos (no así en 1 Cor 14,14-15).

Lo que resulta importante, entonces, es el contraste que podemos llamar "antropológico" 32 . Resulta interesante que algunos en Corinto se crean poseedores del "espíritu", y esos tales -probablemente de las clases altas de Corinto- tienen una actitud de menosprecio a los que -según ellosno lo tienen; el espíritu -pretenden- es algo que poseen unos pocos. El mismo tema se planteará en los caps. 12-14. Algunos, que se ven como "espirituales" $(12,1)$, pretenden que Pablo les reconozca su primacía en la comunidad $^{33}$; estos incluso hacen sentir su inferioridad a los que menosprecian $(12,21)$ e incluso han logrado que estos reconozcan esta supuesta superioridad (12,15-16). Como en 2,6-16, Pablo insistirá en que el espíritu es dado a toda la ekklêsía, y nadie hay sin espíritu (12,7.11). La característica de

30 E. de la Serna, “La iniciativa divina en 1 Cor”, RevistB 51 (1989) 39-44.

31 Conzelmann, 1 Corinthians, 60, 123.

32 R. Bultmann ha insistido en que la antropología está en la base de la escatología y la cristología paulinas, ya que, de hecho, estructura toda su teología: Theologie des Neuen Testaments, Tübingen 1958, 187-353. Allí distingue un esquema animista (animistischer Denkweise) y un esquema dinamista (dynamistischer Denkweise) al hablar del "espíritu". "Hay un consenso en que el don del pneuma es un don escatológico, que su efecto en la comunidad es un acontecimiento escatológico" (157-158).

${ }^{33}$ La insistencia de Pablo en su trabajo manual y en no aceptar dinero de esta comunidad en particular ha de verse en este sentido, cf. E. DE LA SERNA, “La Justificación por la fe. Una mirada teológica del trabajo paulino", RevistB 68 (2006) 101115. 
los "dones espirituales" / "carismas" ${ }^{34}$ es que surgen de la iniciativa divina ("los puso Dios", 12,18.28, o también el "espíritu", "según quiere", 12,11).

Podemos decir del "espíritu" en esta unidad algo semejante a lo que Dale B. Martin ha dicho del "cuerpo" en esta misma carta: la elite de Corinto hace suya una concepción intelectual, ilustrada y de clase alta del "cuerpo", al estilo de Galeno, Hipócrates y el Pseudo-Aristóteles; Pablo -que quizá comparta esta opinión- hace suya una mirada popular del término, quizá más semítica ${ }^{35}$. En este caso, si los individualistas y "sabios" corintios pretenden tener el espíritu, Pablo les destaca que la Iglesia es un "pueblo crucificado" 36 , que la verdadera Sofía -que contrasta con la "carnal", la de los "príncipes de este mundo"-, es revelada, por medio del espíritu, por los que tenemos la mente del Señor. Pablo rechaza el elitismo de algunos en Corinto haciendo propia su opción por los últimos de la comunidad. En este mismo sentido podemos afirmar -con R. Horsley- que el uso paulino del término "espíritu" marca un contraste anti-imperial ${ }^{37}$. Es evidente que Pablo toma del lenguaje imperial una serie de términos, trastocando sus sentidos de un modo contracultural. Estos términos (hijo de Dios, señor, gracia, fe, ekklêsía, paz, evangelio, etc.) y aquí "espíritu" forman parte del corazón mismo de la teología paulina y nos invitan a pensar a Pablo desde una perspectiva subversiva para el Imperio ${ }^{38}$.

${ }^{34}$ Mientras los corintios le preguntan por los "espirituales" (12,1), Pablo prefiere hablar de "carismas" $(12,4)$ y les cambia el término para resaltar el don divino (“distribución", vv. 4-11) por encima de las personas.

35 D. B. MARTIn, The Corinthian Body, New Haven 1999; luego de hablar de ideologías y estatus socioeconómico, señala el conflicto diciendo que "lo que tenemos en la Iglesia de Corinto es, entonces, una división entre aquellos que pueden controlar económicamente su destino y quienes no" (xvii); así contrasta la opinión clásica (18-19) con la postura asumida por Pablo (55-68).

${ }^{36}$ E. de la Serna, “El pueblo crucificado. Aspectos bíblicos”, Proyecto 33 [en Homenaje a Ignacio Ellacuría] (1999) 115-141 (esp. 129-133).

37 Cf. R. Horsley, "Rhetoric and Empire - and 1 Corinthians" [sobre los espirituales y la "posesión de Sofía" en Corinto y el contraste entre esta elite y los sectores marginales], en R. A. HorsLey (ed.), Paul and Politics. Ekklesia - Israel - Imperium - Interpretation (FS. K. Stendhal), Harrisburg 2000, 89-90. Forma parte del uso anti-imperial de la lengua del imperio, aquí utilizada contra los pneumáticos de Corinto (101).

38 Sobre esto, cf. Horsley, Georgi, Elliott lcf. E. DE LA SeRnA, “El desafío paulino ante las autoridades romanas. Lecturas de Romanos 13,1-7", en J. L. D'Amico - C. Mendoza [eds.], La Palabra está muy cerca de ti, en tu boca y en tu corazón (Dt 30,13). Homenaje a G. M. Nápole, Buenos Aires 2015, 312, notas 60 y 61). Sugerentemente, K. Ehrensperger, Paul and the Dinamic of Power. Communication and Interaction in the Early Christ-Movement (LNTS 325), London - New York 2007, 127, añade también el uso de "Padre" (e hijos adoptivos) a esta lista contracultural. 
En suma, el espíritu que algunos de la elite corintia reclamaban exclusivamente para sí mismos, sintiéndose poseedores y despreciando a los sectores marginales, Pablo lo reconoce como un don de Dios para todos sin excepción. Nadie hay sin espíritu, aunque algunos pretendan monopolizarlo por caracterizarse por manifestaciones estruendosas o extraordinarias. La edificación de la comunidad es el criterio fundamental y no la autoexaltación individualista y superficial que caracteriza a los miembros de la elite que se desentienden de los débiles ${ }^{39}$.

\section{El espíritu y la debilidad 1 (Gálatas)}

En la carta a los Gálatas, Pablo entra en conflicto con la comunidad a causa de que han seguido lo que irónicamente llama "otro evangelio" $(1,6)$ y que inmediatamente precisa como una deformación (metastrépsai, v. 7) del mismo ${ }^{40}$. El tema principal de la carta está puesto en el debate con ese "otro evangelio" que predican los "maestros" introducidos en la comunidad.

El judaísmo recibía a los paganos que querían "hacerse judíos"; eran los "prosélitos". Para incorporarse a Israel era preciso un baño de purifica-

39 La astheneia (debilidad) es un tema muy importante en la carta; Pablo afirma que la mayor parte de los miembros de la comunidad lo son $11,25.27$ y contraste con v. 26). Pablo se presenta a sí mismo como "débil" $(2,3)$, lo que contrapone a la actitud de algunos en la comunidad $(4,10)$; algunos se desentienden de los "débiles" y su conciencia $(8,7.9 .10)$, a los que irónicamente afirma que los "edifican a la idolatría" (v. 10). Pablo ha hecho una opción por la "debilidad" (9,22), destacando que los miembros más débiles del cuerpo son los indispensables $(12,22)$. De hecho, para Pablo, la debilidad se asemeja con la cruz, y la resurrección es la fuerza que viene en consecuencia $(15,43)$. El término ciertamente se encuentra en un contexto conflictivo con los que se ven a sí mismos como "fuertes"; cf. C. K. BarRetT, "Eidôlothyta Once More", On Paul. Essays on His Life, Work and Influence in the Early Church, London - New York 2003, 27-35.

40 Quizá haya que relacionar el tema con lo que en 2 Cor 11,4 llama “otro Jesús [...] un espíritu diferente [...] un evangelio diferente" (éteron euaggelíon). En ambos se alude a que los destinatarios han seguido la predicación de otros que distorsionan la predicación de Pablo criticando a su vez al apóstol. En ambas cartas Pablo se ve obligado a realizar una apología. La diferencia radica en que, en Gálatas, Pablo pone su acento en el contenido del Evangelio, mientras que en 2 Corintios resalta su rol como evangelizador; sin duda porque, en la primera, los "maestros" han puesto el acento en la circuncisión y criticado a Pablo, mientras que, en la segunda, la crítica a Pablo va acompañada de un elogio a los "apóstoles excelsos". 
ción, al que muchos llaman "bautismo de los prosélitos" ${ }^{41}$, y luego era necesaria la circuncisión. La teología que Pablo aprende, asume y perfecciona en su estadía en Antioquía ${ }^{42}$ lo lleva a entender que el bautismo "en nombre de Cristo" incorpora plenamente a los paganos en el pueblo de Dios "en Cristo". Ya no hace falta nada más. Otras comunidades, quizá mayoritarias, representadas especialmente por la Iglesia de Jerusalén, entienden que el bautismo es la primera etapa, pero "falta la circuncisión", y eso es lo que reclaman y predican. De ahí la importancia que da Pablo en esta carta al tema del bautismo. Para Pablo, el bautismo es el momento en el que la persona se incorpora plenamente a Cristo y recibe a su vez el espíritu.

Al afirmar "el espíritu que recibieron" $(3,2)$ supone que el tema no está en discusión; la pregunta es por las circunstancias en que lo hicieron. "Pablo quiere partir de la experiencia del espíritu entre los gálatas para poner en discusión su actual orientación" ${ }^{43}$. El espíritu lo hemos recibido por la fe. La semejanza entre Cristo y el espíritu a la que hicimos referencia tiene en el bautismo un punto de partida fundamental, como se ve en el texto paralelo de Gal 3 y 1 Cor 12 .

\section{Gal 3,27-28}

\begin{tabular}{|c|c|}
\hline En efecto, todos los & 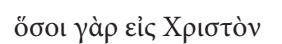 \\
\hline bautizados en & 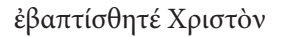 \\
\hline $\begin{array}{l}\text { Cristo se han } \\
\text { revestido de Cristo: }\end{array}$ & 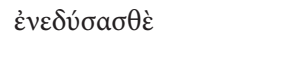 \\
\hline no hay ni judío & 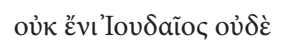 \\
\hline & "E $\lambda \lambda \eta \nu$ \\
\hline sclavo ni libre; & 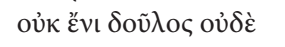 \\
\hline varón y mujer, & 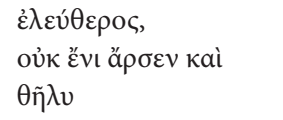 \\
\hline que todos & $\pi a ́ v \tau \varepsilon \varsigma$ үà \\
\hline $\begin{array}{l}\text { des son uno en } \\
\text { to Jesús. }\end{array}$ & 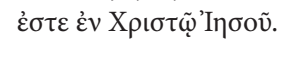 \\
\hline
\end{tabular}

1 Cor 12,13

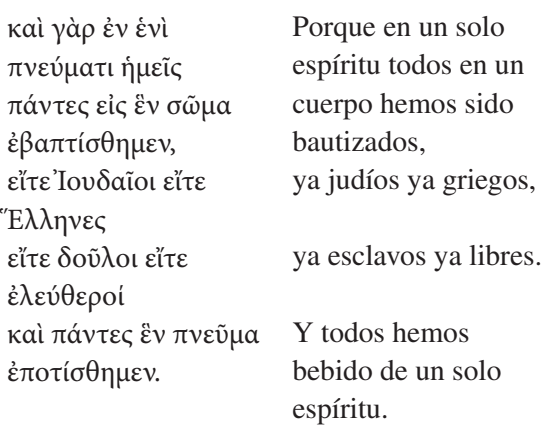

41 J. D. Lawrence, Washing in Water. Trajectories of Ritual Bathing in the Hebrew Bible and Second Temple Literature, Leiden - Boston 2006.

42 Cf. C. K. Barrett, “Christocentricity at Antioch”, On Paul, 37-54.

43 A. PITTA, Lettera ai Galati (SOC 9), Bologna 1996, 164; H. D. BeTz, Galatians (Hermeneia), Philadelphia 1979, 133, afirma que "no es clara la relación del bautismo con esta experiencia [del espíritu]. Pero de todos modos no puede negarse que la experiencia del Espíritu ocurre fuera de la alianza de la Torá, que no es ahora fruto de las 'obras de la Torá"'. 
El bautismo "en Cristo" o "en el espíritu" parece idéntico; sin duda, Pablo lo modifica según el tema que está destacando en cada una de estas cartas: "en el espíritu" frente a los que pretenden ser "espirituales" en Corinto, y "en Cristo" porque destaca "la fe en Cristo" sobre la "ley" en Gálatas ${ }^{44}$.

Este bautismo, resalta Pablo, nos une plenamente al Hijo ${ }^{45}$. Cristo y espíritu, cristología y escatología, vuelven a integrarse en un claro marco antropológico ${ }^{46}$. "El Espíritu es la novedad escatológica de Dios, la presencia apocalípticamente poderosa en el mundo" ${ }^{47}$.

La experiencia del espíritu es -para Pablo- la prueba de la falsedad de la predicación de los maestros. Hay contraste entre maldición $(3,13)$ y bendición (3,14; haciéndose eco de la doctrina de los dos caminos), entre los elementos de este mundo, que nos hacen esclavos, 4,3 (en v. 8 los que nos hacen esclavos son los ídolos; en v. 9 los identifica y enseguida se los

44 Se ha señalado que Pablo parece estar citando un texto bautismal prepaulino. El mismo no incluiría "varón-mujer", que Pablo añade a raíz de la importancia que da al tema de la mujer en 1 Corintios. Lo hemos señalado en E. DE LA SERnA, “El lugar de la mujer en los escritos de Pablo", en E. DE LA SeRnA - J. L. D’Amico (eds.), Donde está el Espíritu está la libertad (FS Luis H. Rivas), Buenos Aires 2003, 381-382. Un tema importante, que no podemos señalar aquí, para una mejor comprensión de los textos es conocer si Gálatas es anterior o posterior a 1 Corintios ly, por tanto, por ejemplo, si añade u omite el par "varón y mujer"). Nosotros creemos que 1 Corintios ha de fecharse antes que Gálatas, cf. J. SÁnchez Bosch, Escritos paulinos, Estella 1999, 65-69; PITTA, Galati, 30-32. Muchos autores anteponen la carta como la segunda de Pablo luego de 1 Tesalonicenses, y tienen en cuenta la "colecta" como criterio estructurante; cf. J. L. MARTYN, Galatians (AB 33A), New York - London - Toronto - Sydney - Auckland 1997, 19-20. Sin duda, la colecta es un elemento valioso para la cronología paulina, pero Pablo mismo afirma que la colecta es organizada en Macedonia y Acaya (cf. 2 Cor 8-9; Rom 15,26); no es claro a qué, cómo o cuándo se refiere en 1 Cor 16,1, cf. D. GEORGI, Remembering the Poor. The history of Paul's Collection for Jerusalem, Nashville 1992.

45 “Pablo usa el arameo abbá dirigiéndose a una audiencia grecoparlante al menos para resaltar que por el Espíritu de su hijo los cristianos tienen hacia Dios la misma actitud que Cristo", ThISELton, Holy Spirit, 79.

46 Con justicia -creo- destaca lo antropológico S. Butticaz, "Vers une anthropologie universelle?", aunque no dedica casi lugar alguno al espíritu en su trabajo. Lo mismo hemos de decir de S. GrindHeIm, “Not Salvation History, but Salvation Territory: The Main Subsect Matter of Galatians", NTS 59 (2013) 91-108. En su intento por resaltar la importancia de lo espacial ante lo temporal (confrontando con J. L. Martyn) no dedica casi espacio alguno al espíritu. En cambio, Butticaz remarca al menos lo "teo-antropológico" (siguiendo a Martyn), resaltando lo apocalíptico y lo "escático" lasí lo llama -no "escatológico"- siguiendo sugerentemente a M. Wolter) "inaugurado por la cruz".

47 M. C. DE Boer, Galatians (The New Testament Library), Westminster 2011, 183. 
relaciona con la "ley"), y el rescate de esto que nos provoca la adopción filial. Es interesante que, en ambas unidades, el espíritu ocupa un lugar central: la fe nos permite recibir el espíritu, y Dios envió a su Hijo al llegar la plenitud de los tiempos.

Es impensable "volver atrás" (nótese este tema centralmente escatológico en relación con el espíritu), ya que Pablo insistirá en la insensatez, siendo libres por el Hijo, de volver atrás, a la esclavitud de los "elementos de este mundo" o de "la ley" 48 . Así se entiende el refuerzo del "envío" por parte de Dios "del Hijo" (v. 4) y "el espíritu" (v. 6), y que sea llamado "espíritu de su hijo" (cf. Flp 1,19; 2 Cor 3,17). Así, el espíritu "constituye la propia presencia continua invasiva -apocalíptica- de Dios y su actividad en el mundo de los seres humanos" ${ }^{49}$. No somos guiados -esclavos- por la ley, sino por el espíritu $(5,18)$, que nos lleva a entrar en intimidad con Dios.

Así se entiende el contraste entre caminar según el espíritu y cumplir los deseos de la carne (5,16-17). El contraste "carne-espíritu" marca el sentido escatológico de esta antropología. "Si vivimos por el espíritu, al espíritu también sigamos" $(5,25)$, algo reflejado en las "obras de la carne" y el fruto del espíritu, ante el que "no hay ley" (5,23). La idea la retomará en la carta a los Romanos.

\section{El espíritu y la debilidad 2 (Romanos)}

La carta a los Romanos termina su primer gran unidad (1-8) dedicada a mostrar los efectos de la gracia en los creyentes. El gran efecto (ya preparado en la carta a los Gálatas, que muchos autores ven como una gran inspiradora de la carta a los Romanos) es la libertad. El creyente es libre, a diferencia de los que están sometidos a sus propias (in)capacidades o a la misma Ley (caps. 1-3). Pero no es libre por su propia fuerza, sino por la gracia de Dios. Esta nos "sumerge en Cristo", y por tanto hemos abandonado el ámbito de la debilidad (= carne) para dejarnos conducir por la fuerza de Dios en nosotros, que es el espíritu. Sin ese espíritu, ciertamente, recaería-

48 Resulta interesante que, en la primera referencia a los "elementos" (4,3), Pablo habla de "nosotros", incluyendo, evidentemente, su pasado judío, mientras que en la segunda $(4,9)$ se dirige a "ustedes". Seguramente, al ser "esclavo" de la ley en su pasado, Pablo compara elementos como el sábado o la Pascua con los elementos como el sol o la luna, entendiendo que ambos grupos esclavizan. En cambio, el "ustedes" de v. 9 contrasta el pasado y el presente del ser "menores de edad" y de ser conocidos por Dios en la "plenitud de los tiempos".

49 De Boer, Galatians, 266. 
mos en la incapacidad que nos impide vivir según Dios, "en Cristo". Sin Cristo "no pueden" (ou dynantai, v. 8, cf. v. 7). El contraste es, evidentemente, entre la "carne" y el "espíritu"; se trata de dos mundos (eones), dos horizontes. La carne es expresión de nuestra propia incapacidad, mientras que el espíritu es "de Dios"; solo quien tiene el espíritu de Dios puede "agradar a Dios", es decir, vivir conforme a lo que Pablo ha enseñado (1 Tes $4,1)$, buscando agradar a los hermanos (Rom 15,1-3), a todos (1 Cor 10,33) por Dios (cf. Gal 1,10).

Aquellos que en el bautismo han recibido el espíritu de hijos ya no están "en la carne", el espíritu "habita" en ellos $(8,9.11$; cf. 1 Cor 3,16$)$. Sin ese espíritu, el que "habita" es el pecado $(7,17.20)$, "nada bueno habita en mí" $(7,18)$ (el verbo "habitar", enoikéô, es exclusivamente paulino en el Nuevo Testamento).

Este contraste entre carne y espíritu se refleja en otro contraste: pecado-justicia, muerte-vida (v. 10) (hay que notar que lo que muere es el "cuerpo"; no dice "carne"). La muerte ha entrado en el mundo como consecuencia del pecado $(5,12)$, la vida ha reinado a causa de la justicia: "En efecto, si por el delito de uno solo reinó la muerte por un solo hombre, ¡con cuánta más razón los que reciben en abundancia la gracia y el don de la justicia reinarán en la vida por uno solo, por Jesucristo!" $(5,17)$. La vida que los "cuerpos mortales" recibirán de parte de aquel que "resucitó a Jesús" es dada por mediación de ese espíritu de Dios que habita en nosotros (v. 11).

Pablo da un cierre a toda la primera parte de la carta estableciendo fundamentalmente un contraste con el ser humano de la debilidad, la ley y el pecado que ha presentado en el cap. 7: con Cristo hemos sido liberados del pecado, la muerte y la ley, pero no es eso lo que experimentamos. Ante esa debilidad la persona se encuentra sin salida: ¿quién me librará? (v. 24), no hago el bien que quiero, sino el mal que no quiero (v. 19), es el pecado el que habita en mí (v. 17). Ese ser humano sin salida encuentra otro camino:

Pues lo que era imposible a la ley, reducida a la impotencia por la carne, Dios, habiendo enviado a su propio Hijo en una carne semejante a la del pecado, y en orden al pecado, condenó el pecado en la carne, a fin de que la justicia de la ley se cumpliera en nosotros que seguimos una conducta, no según la carne, sino según el espíritu (8,3-4).

Ese ser humano que se dirigía a la muerte encuentra súbitamente abierto el camino hacia la vida, algo expresado -como es frecuente en $\mathrm{Pa}$ blo- en los términos "carne" y "espíritu". Estos términos son los que marcan el ritmo de esta unidad, pero han de entenderse en un sentido "escatológico", es decir, señalando la llegada del fin de los tiempos -comenzado en la resurrección de Cristo, a la que nos unimos plenamente por el bautis- 
mo-, en la cual el espíritu es el don por excelencia recibido por los que creen. Los que no creen, en cambio, están precisamente ante esa debilidad sin salida (la "carne") de la que hablaba en el cap. 7. Podríamos parafrasearlo de este modo: "Ustedes no están en el tiempo de la carne, sino en el tiempo del espíritu"; pertenece a Cristo (es de Cristo) quien tiene su espíritu. El v. 10 hace referencia a la muerte, que es consecuencia del pecado $(5,12.21 ; 6,23 ; 7,13 ; 8,2)$, y a la vida, fruto del espíritu por la justicia que viene de la fe $(1,17 ; 3,22.25 .26 .28 .30 ; 4,3.5 .9 .11 .13 ; 5,1 \ldots)$. Ese espíritu que Dios ha transmitido es dador de vida, como ya lo ha mostrado al resucitar a Jesús de entre los muertos; por eso nuestros cuerpos, que caminan hacia la muerte, recibirán ese mismo espíritu dador de vida $(1 \text { Cor } 15,45)^{50}$.

Así, los creyentes no deben nada a la carne, sino al espíritu, y por tanto están frente a dos opciones (dos caminos, como es frecuente en la literatura bíblica): la vida y la muerte, ya vivan "según la carne" o "según el espíritu" (v. 13).

Luego de destacar que, gracias a la plena unión con Cristo (= gracia), somos libres del pecado, de la muerte y de la ley, finaliza destacando que esto ocurre por la donación plena del espíritu, el don escatológico por excelencia.

Con esta idea comienza el fragmento sobre "los que se dejan guiar por el espíritu de Dios" (v. 14). Al recibir el espíritu se produce una suerte de fusión de todos los espíritus con el espíritu de Dios. Muy probablemente Pablo tenga en mente la imagen bautismal. Al sumergirse, todos son/están "en Cristo", y son "hijos en el Hijo", usando palabras de Agustín. Esta filiación adoptiva ${ }^{51}$ es, para Pablo, algo propio de Israel (huiothesía; cf. 8,23; Gal 4,5; cf. Ef 1,5). De Israel

es la adopción filial, la gloria, las alianzas, la legislación, el culto, las promesas y los patriarcas; de los cuales también procede Cristo según la carne, el cual está por encima de todas las cosas, Dios bendito por los siglos. Amén (Rom 9,4).

50 Además de decirse de Dios, también se dice del espíritu (recién en el NT) que “da vida" (Jn 6,63; Rom 8,11; 1 Cor 15,45; 2 Cor 3,6; 1 Pe 3,18), y solo de ellos se afirma en la Biblia; el "espíritu" es dador de vida porque es "de Dios". El espíritu de Dios es el dador de vida (cf. Gn 2,7; Job 33,4; Sal 104,29-30; Ez 37,9-10; Rom 8,11; 2 Cor 3,6 y Rom, 8,2).

51 Es interesante notar que el AT desconoce la “adopción”. Esta la recibe del derecho romano y la utiliza en clave bautismal. El Código de Hammurabi prevé que un hombre adopte a los hijos de su esclava (n. 170) y dedica a los derechos de los adoptados los nn. 185-194. Cf. Ph. F. EsLer, Conflicto e identidad en la carta a los Romanos. El contexto social de la carta de Pablo, Estella 2006, 344-347. 
Precisamente por hijos somos herederos. Israel, al salir de Egipto, se dirige al "monte de tu herencia" (Ex 15,17), a la tierra que hereda (Dt 12,9), porque "la porción de Yahvé fue su pueblo, Jacob la parte de su herencia" (Dt 32,9); el rey es "jefe de la herencia de Dios" (1 Sam 10,1)... Pero al ser hijos por estar unidos a Cristo "son descendencia de Abrahán, herederos según la promesa” (Gal 3,29).

La unión (bautismal) con Cristo, el Hijo de Dios, hace a los creyentes ser adoptados también ellos como hijos. El contraste viene dado al destacar que "no han recibido el espíritu de esclavos" para volver al temor. El contraste hijos-esclavos fue usado con mucho provecho por Pablo en Gal 4,1-7 para resaltar la llegada del tiempo establecido por el Padre para percibir la herencia.

Pablo había dicho que nadie puede decir "Jesús es Señor" si no tiene el espíritu de Dios (1 Cor 12,3); ahora señala que la oración confiada que se dirige a Dios como "Abbá-Padre" 52 es un testimonio de la unión de nuestro espíritu con el espíritu de Jesús y, por tanto, de que somos verdaderamente -como él- hijos de Dios. A diferencia de Gálatas, "Pablo [...] presenta la filiación divina [...] como un apoyo para exigir que vivan en el Espíritu y no en la carne" 53 .

En el v. 17 había dicho que "si sufrimos, seremos glorificados con él". Partiendo del tema del sufrimiento, aunque ahora tematizado y universal (“toda la creación”), Pablo da un paso más marcado por la esperanza. Una serie de elementos caracterizan el presente: sufrimientos, gemidos, dolores (de parto), paciencia, pero nada de esto impedirá la llegada de la gloria, que se manifestará, revelación, liberación, rescate. La esperanza es parte fundamental (vv. 24-25). El espíritu, que era fundamental en el párrafo anterior, cede su lugar a otra perspectiva marcada por el presente (vv. 18.22) y el futuro (vv. 18.19.20.23.24.25), preparado con las imágenes del parto y las primicias (vv. 22.23).

52 El término es arameo y dice "padre" desde una perspectiva cargada de respeto y confianza. El término solo se encuentra $3 x$ en el NT ( $2 x$ en Pablo, en nuestro texto y en el paralelo de Gálatas que hemos señalado, 4,6, y una vez en los evangelios, en el relato de la pasión, con Jesús en Getsemaní, Mc 14,36). Siendo que Jesús hablaba arameo, y que en todas las oportunidades en que se dirige a Dios lo hace llamándolo "Padre" (la única excepción es en la cruz, citando el Sal 22: "Dios mío, Dios mío..."), lo más probable es que las comunidades hayan conservado el término arameo porque fue usado por Jesús. Abbá no existe en ningún caso que conozcamos en oraciones para dirigirse a Dios (sí hay algunos textos en los que se usa “padre mío" en hebreo, 'abî, por ejemplo en Qumrán). También esta discontinuidad es indicio de que Jesús ha de haberlo usado frecuentemente e invitado a los suyos a hacerlo también.

53 EsLer, Conflicto e identidad, 346. 
La recurrencia de la creación (ktisis) ubica el relato en un afuera del ser humano, un horizonte en el que este se ve incluido, pero no lo agota. Quizá por eso no hable de resurrección, sino de corrupción, caducidad, sufrimiento, y liberación o rescate. Por otra parte, el texto está en las antípodas de las imágenes que piensan que "este mundo" es perverso o que todo lo positivo se vivirá exclusivamente en un futuro indeterminado. Las "primicias" (v. 23), el espíritu, el primogénito de muchos hermanos (v .29) nos recuerda que es en el "aquí y ahora" que debemos vivir, en el presente histórico, mirando su cumplimiento en esperanza. En realidad, lo anunciado en el v. 18 se desarrolla en los vv. 19-22, refiriendo a toda la creación, en los vv. 23-25, a los cristianos ("y no solo en ella, también nosotros"), y en los vv. 26-27 retorna el tema del espíritu ("y de igual manera el espíritu") como fundamento de la vida cristiana.

El espíritu se manifiesta en contraste con la debilidad (astheneía). Es sabido que el "espíritu" es la fuerza que viene de Dios para sostener (synantilambanô, venir en nuestra ayuda), se hace cargo de nuestra debilidad, el camino de los llamados a seguir su voluntad y sus caminos. La debilidad, en suma, es propia de todo ser humano sin Cristo-espíritu; al recibirlo, el ser humano es fortalecido, recibe la fuerza de Dios. Con nuestras limitaciones, ni siquiera sabemos cómo pedir (proseújomai), de ahí que el espíritu interceda (hyperentugjanei, única vez en la Biblia) con "gemidos" (la otra vez que se encuentra en el NT -Hch 7,34- traduce el término "clamores" [cf. Ex 2,24; 6,5]). Estos gemidos no son la voz de un bebé, sino los gritos del dolor, la opresión y el sufrimiento, y por eso son "inexpresables" (alálêtos, literalmente: "sin palabras", también única vez en la Biblia). El contraste entre "debilidad"-carne y espíritu no es algo que dependa de la mera decisión humana, sino que nace de la iniciativa divina (gracia) y es recibido (fe) por varones y mujeres "en Cristo".

El verbo eraunáô, "investigar/sondear/escrutar", no es muy frecuente en la Biblia (6x) y suele referirse a la voluntad de Dios. En este caso, "el que escruta los corazones" (= Dios) conoce las aspiraciones íntimas del espíritu. "Conocer/tender" (frónêma) es también poco frecuente ${ }^{54}$, aunque depende hacia dónde se tienda (la carne o el espíritu, 8,6). En este caso se refiere a tender hacia el espíritu, por lo que la "intercesión" (entugjanô) es "según [kata] Dios" y "en favor [hyper] de los santos" (es decir, los miembros del pueblo de Dios). El espíritu, don por excelencia de Dios para los tiempos nuevos, nos hace tender en sentido contrario a lo que nos separa de

$542 \operatorname{Mac} 7,21 ; 13,9 ;$ Rom 8,6 (2x).7.27. 
Dios; por el contrario, nos hace tender a la vida, interceder coherentemente con la voluntad de Dios.

En el v. 26 dijo que el espíritu de Dios viene en ayuda de nuestra debilidad, permitiéndonos intervenir y pedir de modo que esto sea según Dios (v. 27). El texto ahora nos señala que Dios interviene (synergei) en favor (para bien, agathon) de los que le aman, de los que fueron llamados. El acento está puesto en una "cadena" de verbos que se interrelacionan. Pablo recurre a este estilo en otras ocasiones en la misma carta (cf. 10,14-15).

Allí los verbos son invocar-creer-oír-predicar-enviar (obviamente tienen como punto importante el primero de los verbos, "invocar", pero esto no es posible sin haber sido "enviados"). Del mismo modo en nuestro texto: conoció-predestinó-llamó-justificó-glorificó. En este caso, la glorificación (edóxasen) es la conclusión de un proceso que comienza con el conocimiento que Dios tiene y por el cual llama. La larga lista de verbos es sumamente importante, y cada uno merecería un párrafo. Todos se encuentran en aoristo, por lo que se refieren a un momento concreto y puntual del tiempo pasado.

- "Conoció de antemano" (proginôskô) puede aludir a un conocimiento que ya lleva tiempo (Sb 18,6; Hch 26,5; Rom 11,2), a estar prevenidos $(2 \mathrm{Pe} 3,17)$ o al conocimiento por parte de Dios (que puede ser anterior al tiempo, 1 Pe 1,20).

- "Predestinó" (proorizô) es un verbo ligado a la "elección" (cf. Ef $1,5.11)$ y a la gloria futura (1 Cor 2,7); dice relación al plan de Dios de salvación (Hch 4,28). En este caso, antes del siguiente verbo hará explícita esta predestinación de los que conoce: "reproducir la imagen" del Hijo. Con el objetivo de que no sea "hijo único", sino "primogénito" de "muchos hermanos".

- "Llamó" (ekálesen) es un verbo obviamente "vocacional" y alude con frecuencia a Israel (9,7.12.24.25.26), pero también al llamado a la fe, a la comunidad cristiana (cf. 1 Cor 1,9; 7,15.17.18.20.21 ...; Gal $1,6.15 ; 5,8.13)$.

- "Justificó" (dikaióô) es un verbo clave de toda la carta a los Romanos (15x). Dios reconoce como justos a aquellos que creen en Cristo. Aquellos a los que, porque son conocidos por Dios, él los prepara para repetir la "imagen" de su Hijo; de ahí que los llame para que, creyendo, sean justos ante Dios.

- "Glorificó" (doxazô) es dar gloria. Lo frecuente es "dar gloria a Dios" $(1,21 ; 15,6.9)$, pero puede significar que alguien "hable bien" de una persona $(11,13 ; 1$ Cor 12,26), con lo que se asemeja a "bendición". 
El cristiano, al poseer el espíritu, ha sido liberado de la ley del pecado y de la muerte $(8,2)$; de ahí que en cierto modo ya participe plenamente de la gloria de Adán (cf. 3,23) ${ }^{55}$.

Todo el cap. 8 finaliza con un himno formado por una larga serie de preguntas retóricas que suponen una respuesta negativa: ¿quién estará contra nosotros? ¡Nadie! ¿Quién acusará? ¡Nadie! ¿Quién podrá separarnos? ¡Nadie! Ni siquiera las situaciones conflictivas más duras (tribulaciones, angustias, persecución, hambre, desnudez, peligros o espada). El contexto de violencia de los conflictos recién mencionados invita a notar que hambre y desnudez en este caso parecen entenderse como consecuencia de una invasión y derrota militar. Ni siquiera estas situaciones de violencia extrema -a las que somos sometidos por "la causa" de Dios/Jesús (la cita del Salmo 44 alude a Dios, mientras que la cita en su contexto alude a Cristo)nos pueden separar del amor que Cristo tiene por nosotros (amor "de" Cristo es subjetivo).

La lista de dificultades es algo frecuente en la antigüedad. Era frecuente la presencia de "catálogos", en este caso de dificultades. Veamos a modo de ejemplo en los Testamentos de los Doce Patriarcas lo que cuenta "José":

${ }^{3}$ Yo vi en mi vida la envidia y la muerte, pero no me desvié por la fidelidad del Señor.

${ }^{4}$ Mis hermanos me odiaron, pero el Señor me amó;

ellos quisieron matarme, pero el Dios de mis padres me guardó.

A una cisterna me bajaron, pero el Altísimo me sacó.

${ }^{5}$ Fui vendido como esclavo, pero el Señor me liberó.

Fui llevado a la cautividad, pero su mano poderosa me ayudó.

Me sentí agobiado por el hambre, pero el Señor me alimentó.

${ }^{6}$ Estuve solo, pero Dios me consoló;

estaba enfermo, pero el Altísimo me visitó.

Yacía encarcelado, pero el Salvador se apiadó de mí.

Entre grilletes estaba, pero él me desató.

${ }^{7}$ Me vi rodeado de calumnias, pero él me defendió;

entre terribles palabras de los egipcios, pero él me salvó;

entre las envidias de mis consiervos, pero él me exaltó

(Testamento de José 1,3-7)

Como puede verse -y es lo habitual-, el primero de los miembros de la lista es el que sintetiza el todo; en nuestro caso la "tribulación" (thlipsis), que puede entenderse como la característica de las dificultades de los tiempos escatológicos.

55 "Pablo ha hablado de la primicia del Espíritu, ya donado a los cristianos (cf. v. 23), y esta representa en cuanto tal una segura anticipación del futuro", R. PENNA, Lettera ai Romani, II, Rm 6-11 (SOC 6), Bologna 2006, 204 (hay ed. castellana). 
La cita del salmo - un canto del justo que sufre, en este caso en sentido colectivo- es más bien ilustrativa antes que demostrativa. Los salmos del justo sufriente han sido muy tenidos en cuenta por el cristianismo primitivo y relacionados con los Cantos del Siervo sufriente de Yahvé para ligarlos a la pasión de Cristo y para comprender los momentos críticos de los cristianos.

Estas dificultades finalizan con un canto de triunfo: "vencemos", pero no gracias a nuestra capacidad o fortaleza, sino al mismo amor de Cristo ("aquel que nos amó" [también puede referir a Dios]). La debilidad propia es sostenida por la fuerza de Cristo (2 Cor 12,9: "Me jactaré de la debilidad para que habite en mí la fuerza de Cristo [...] cuando soy débil soy fuerte").

A modo de conclusión, Pablo señala otra larga lista de cosas que "no podrán separarnos del amor de Dios manifestado en Cristo". Nuevamente un elenco de dificultades, pero ahora con elementos contrapuestos: muerte/ vida, presente/futuro, altura/profundidad, pero más abstractos que los anteriores.

Esta nueva lista tiene una nueva conclusión positiva ("estoy seguro", v. 38) a las preguntas retóricas que hemos visto y comentado. La respuesta negativa que se presuponía es explicitada claramente: ¡nada!/¡nadie! “podrá separarnos".

La fórmula "Cristo Jesús, Señor nuestro" es una fórmula conclusiva en varias partes de la carta $(1,7 ; 5,1.11 .21 ; 6,23 ; 7,25)$, y en este caso concluye no solamente el cap. 8, sino también toda la primera gran parte de la carta a los Romanos para dar comienzo a una nueva unidad (caps. 9-11), donde afrontará un tema totalmente nuevo.

Como lo había hecho en Rom 3,27.31, en 8,2 Pablo habla de la ley en sentido positivo. En los primeros habla de la ley de la pistis; aquí se habla de la ley "del espíritu". La sección exhortativa de Romanos (caps. 1215), al igual que las exhortaciones de las otras cartas paulinas, surge de esta ley espiritual, la ley de Cristo de Gal 6,2.

Esta ley no es una exigencia, una norma o autoridad. Es más bien un ambiente de lealtad y solidaridad, de fidelidad y confianza, de espíritu y de comunidad. Así, la ley se convierte en una entidad profética, una expresión de poder creativo e imaginación. Establece que ni el pasado ni el presente atan o limitan el futuro. Abre el futuro y es un mensaje de libertad ${ }^{56}$.

56 D. Georgl, “God Turned Upside Down”, en R. A. Horsley (ed.), Paul and Empire. Religion and Power in Roman Imperial Society, Harrisburg 1997, 155. 
Sinteticemos afirmando que "Pablo insiste en que la posesión del Espíritu es el sine qua non de la existencia cristiana ${ }^{57}$.

\section{Conclusión}

La predicación de Pablo fue manifestación de "espíritu y poder" (1 Cor 2,4 [quizá "espíritu que es poder"]); el espíritu es la ayuda en la predicación, predicación del Crucificado, no otra (v. 2). Como la cruz es debilidad, pero en ella actúa el poder de Dios, lo mismo ocurre con la predicación (2 Cor 13,4); por eso, "cuando soy débil es que soy fuerte" (2 Cor 12,10). En la cruz puede verse el obrar de Dios, lo que "ningún ojo vio", lo que "Dios reveló por el espíritu" -algo incomprensible para la sabiduría humana- es "sabiduría de Dios", "insensatez" para el que no sabe del espíritu (1 Cor 1,18-2,16).

Así, al hablar de "espíritu" y "carne", aunque la formulación no sea ajena a la del tiempo (Qumrán, Filón), para Pablo se contrastan dos modos de vida, "según la carne" y "las obras de la ley", por un lado, y "según el espíritu", una "vida nueva" (Gal 3,2-3; Rom 2,29; 7,5-6), por el otro. Así, lo opuesto (como en el AT) a la "carne" es Dios mismo (no el espíritu; cf. 1 Cor 1,26; 2 Cor 1,12; 10,4; 11,17-18; Flp 3,3-7). Lo que cuenta es sobre qué se edifica la vida; lo carnal es lo humano, incluso el propio esfuerzo (no está lejos de la idolatría) o también lo psíquico (1 Cor 2,14; 15,44-49). Se trata de lo meramente "terreno". El "moralista" -los que se creen fuertes- pone su confianza en la "carne", y desde su "creerse moral", "intachable", evalúa y juzga a los demás. Así la ley conduce al pecado (Rom 5,20). Solo está abierto a Dios quien no se cree suficiente y, por tanto, se sabe necesitado de Dios y de su amor. Espíritu es, por el contrario, el accionar de Dios en la vida del ser humano. Eso está reflejado en los dos hijos de Abrahán (Gal 4,23, según la carne y según la promesa). En Flp 3,3 contrasta la vida "en" la carne con la vida "por" el espíritu; una cosa es aquello en lo que el ser humano confía y otra el espíritu que actúa y da la vida; es Dios que actúa en nosotros. El contraste está dado entre obras de la carne, lo que hacemos (y puede cuantificarse), y el fruto (singular) del obrar del espíritu.

Tan importante es la irrupción del espíritu en la persona que Pablo la compara con la liberación del esclavo (Gal 4,6-7.25-26; 5,1-5; Rom 8,1516.21), donde está el espíritu está la libertad (2 Cor 3,17), y que Dios nos amó "siendo todavía pecadores" (Rom 5,8). Así entendemos a Dios como

57 C. G. Kruse, Paul's Letter to the Romans, Grand Rapids - Cambridge 2012, 334. 
presente en medio de nosotros como Abbá (Gal 4,6-7; Rom 8,15-17); el espíritu, su gran don, nos permite "dejarlo actuar en nosotros". Esto hace al ser humano moverse en "otro aire" (en Cristo / en el espíritu y Cristo en nosotros y el espíritu en nosotros son paralelos, Rom 8,1-10). Es un don del espíritu ser lavados, santificados y justificados (1 Cor 6,11). El espíritu viene a nosotros como el espíritu de la promesa que mira hacia el futuro (Gal $3,14)$, futuro de Dios $(5,5)$. Esto nos lleva a una apertura hacia los demás, miembros de un cuerpo por la acción del espíritu (1 Cor 12,13), miembros de una comunidad; el amor es el primer (si no el único) fruto del espíritu (Gal 5,22; Rom 15,30; cf. 1 Cor 13).

Habida cuenta de que los fenómenos extáticos también se daban en grupos fuera de la comunidad eclesial, para Pablo el primer criterio de evaluación es la confesión de fe ("Jesús es Señor", 1 Cor 12,2-3; cf. Rom 10,10). El siguiente criterio es el provecho común (1 Cor 12,7); si no se llega a la comunidad/comunión como un todo, no está allí el espíritu de Dios. El criterio conduce a la edificación de la comunidad (cf. Rom 12,14.17.21). No es ese espíritu "descontrolado" el criterio fundamental; el criterio para Pablo es el amor; "el amor edifica" (1 Cor 8,1).

La resurrección todavía no ha ocurrido, vivimos todavía en este cuerpo (1 Cor 15,44), pero existe un cuerpo "espiritual" que poseeremos resucitados. En Cristo, el espíritu creador nos proporcionará una vida real; pero este "espíritu dador de vida" ya ha irrumpido en nuestra vida (Rom $6,5-8)$, de algún modo ya se hace visible (2 Cor 4,11 ), ya lo atestigua (Rom 8,16). Recibimos un espíritu de adopción (Rom 8,15), espíritu de la promesa $(\mathrm{Gal} 3,14)$.

La resurrección revela un Dios que interactúa con el mundo, y el espíritu es la experiencia más prominente de esta interacción. La obra del espíritu es transformar a los cristianos en la semejanza divina (2 Cor 3,18), que es Cristo (4,4); así el espíritu es "espíritu de Cristo" (Rom 8,9), "del Hijo" (Gal 4,6), "de Jesús Cristo” (Flp 1,19), “del Señor” (2 Cor 3,17). La relación entre Cristo y su espíritu es sumamente estrecha, como también se ve en los textos "triádicos" en los que el Padre, el Señor y el espíritu aparecen interactuando como fuente de gracia. Es interesante que la relación -por el espíritu - con el Padre haga exclamar Abbá y la relación con Jesús -por el espíritu- haga exclamar "Señor" (Rom 8,15; 1 Cor 12,3); una doble relación en el culto es atribuida al espíritu ${ }^{58}$.

58 S. GuiJarro, "El Dios de los primeros cristianos", lección inaugural en la solemne apertura del curso académico 2015-2016 de la Universidad Pontificia de Salamanca, Salamanca 2015, 39-40. 
Por eso Pablo exhorta a los cristianos a vivir "una vida nueva" (Rom $6,4)$ coherente con su bautismo, y a no acomodarse "al eón presente" (Rom 12,2).

Notemos, para concluir:

Los cristianos son la vanguardia de la nueva creación en un mundo y una historia ya viejos. Han muerto con Cristo al poder del pecado, a la humanidad vieja, a los viejos comportamientos del ser humano, pero no participan todavía en la resurrección de Cristo en el bautismo (Rom 6,1-11). Por consiguiente, Pablo puede hablar de morir a la "humanidad vieja" [...] Los bautizados entran en la nueva era, pero aún deben realizar día tras día su ser "en Cristo" ${ }^{59}$.

Es interesante -complementariamente-que, en un primer momento (1987), Elisabeth Schüssler entendiera que

Pablo insiste en el poder transformador de lo nuevo para la vida y la práctica personal cristianas, especialmente en el dominio de la fe, pero no presta suficiente atención a la realidad política concreta de la crucifixión de Jesús. Y por ello no hace hincapié en que el poder de lo nuevo debe hacerse igualmente efectivo en las relaciones socio-políticas cristianas (239).

Pero años después (2000) dirá que:

Las diferencias y contradicciones en la retórica de las fuentes cristianas primitivas apuntan a los conflictos socio-políticos y las tensiones religiosoculturales entre los movimientos "igualitarios" -sean helenísticos, judíos o cristianos primitivos- y sus contextos socio-político-religiosos de dominio kyriarcal. Estas diferentes y contradictorias formaciones socio-retóricas apuntan a los conflictos sociopolíticos dentro de las primeras comunidades cristianas, que se entienden a sí mismas como una "democracia pneumática". Estas tensiones retóricas se pueden rastrear entre los que abogan por el ethos de ekklêsía tanto como una "basileia, discipulado de iguales", y como "una comunidad de libertad en el Espíritu", por una parte, y aquellos que abogan por el liderazgo de la élite kyriarcal de poder masculino y la institucionalización de la ekklêsía kyriarcal, por otra ${ }^{60}$.

Las lecturas en contexto de los escritos paulinos han ido ampliando horizontes. Y en esta ampliación la experiencia del espíritu -tema central del pensamiento del Apóstol- no puede quedar ajena.

Este tipo de experiencias y la convicción de que el Espíritu tenía un papel clave en el reconocimiento de Jesús como Señor fueron ayudando a los discípulos de la primera generación a descubrir que dicho Espíritu formaba parte de la nueva imagen de Dios que se estaba revelando.

59 E. Schüssler Fiorenza, En memoria de ella, Bilbao 1989, 238.

60 E. Schüssler Fiorenza, "Paul and the Politics of Interpretation", en Horsley, Paul and Politics, 56. 
Esta intuición se hizo más explícita en algunos grupos, que percibieron una relación particular entre Jesús y el Espíritu. En algunos pasajes de las cartas paulinas, en efecto, el Espíritu se vincula especialmente a Jesús, de tal modo que ya no se habla del "Espíritu de Dios", sino del "Espíritu de Jesús". Esta forma de definir al Espíritu revela una nueva visión del Espíritu que tiene dos acentos particulares. Por un lado, el hecho de vincular el Espíritu a Jesús supone que Jesús asume un papel propio de Dios. Por otro, al establecerse esta relación, el Espíritu queda definido con los rasgos de Jesús, permitiendo así discernir qué experiencias espirituales son propiamente cristianas $^{61}$.

Podemos decir que

el fondo antropológico de toda esta reflexión [sobre el Espíritu y el pecado] es claro: las fuerzas del mal han penetrado en el hombre y en el mundo hasta tal punto que lo han devastado espiritualmente [...] el espíritu, potencia creadora de Dios según la tradición bíblica, es principio de vida nueva, liberador de la ley del pecado y de la muerte (Rom 8,2), entregado a los creyentes como dinámica alternativa opuesta a la "carne" 62 .

Los débiles, los pobres, los despreciados por la cultura hegemónica encuentran en el espíritu de Jesús la capacidad, la iniciativa divina que les permite experimentar la fuerza de Dios presente en el mundo y en la historia para cambiarla. La experiencia del espíritu es profundamente subversiva, especialmente al constatar nuestra debilidad frente a "los príncipes de este mundo" o "los elementos", ya que permite que no sean ellos los que tengan la última palabra, sino que la tengamos los que "vivimos según el espíritu” y, por ello, "obremos según el espíritu” (Gal 5,25).

EDUARDO DE LA SERNA

${ }^{61}$ Guijarro, "El Dios de los primeros cristianos", 53-54.

62 Barbaglio, Teología de san Pablo, 455. 